\title{
Visceral obesity: A new risk factor for stone disease
}

\author{
Ilker Akarken, MD; Hüseyin Tarhan, MD; Rahmi Gökhan Ekin, MD; Özgür Çakmak, MD; Gökan Koç, MD; ${ }^{\dagger}$ \\ Yusuf Özlem İlbey, MD; Ferruh Zorlu, $M D^{+}$
}

*Kemalpasa State Hospital, Urology Clinic, Turkey; ${ }^{\dagger}$ Tepecik Teaching and Research Hospital, Department of Urology, Turkey

Cite as: Can Urol Assoc J 2015;9(11-12):E795-9. http://dx.doi.org/10.5489/cuai.3145 Published online November 4, 2015.

\section{Abstract}

Introduction: We examined the relationship between stone disease and the amount of visceral adipose tissue measured with unenhanced computed tomography (CT).

Methods: We included 149 patients with complaints of flank pain and kidney stones detected by CT, from August 2012 to April 2013. In addition, as the control group we included 139 healthy individuals, with flank pain within the same time period, with no previous history of urological disease and no current kidney stones identified by CT. Patients were analyzed for age, gender, body mass index, amount of visceral and subcutaneous adipose tissue, and serum level of low-density lipoprotein and triglyceride.

Results: There were no differences between groups in terms of gender and age ( $p=0.27$ and 0.06 , respectively). Respective measurements for the stone and control groups for body mass index were 29.1 and $27.6 \mathrm{~kg} / \mathrm{m}^{2}$; for visceral fat measurement 186.0 and 120.2 $\mathrm{cm}^{2}$; and for subcutaneous fat measurements 275.9 and $261.9 \mathrm{~cm}^{2}$ ( $p=0.01 ; 0.01$ and 0.36 , respectively). Using multivariate analysis, the following factors were identified as increasing the risk of kidney stone formation: hyperlipidemia $(p=0.003)$, hypertension $(p=0.001)$, and ratio of visceral fat tissue to subcutaneous fat tissue $(p=0.01)$. Our study has its limitations, including its retrospective nature, its small sample size, possible selection bias, and missing data. The lack of stone composition data is another major limitation of our study.

Conclusion: The ratio of visceral to subcutaneous adipose tissue, in addition to obesity, hyperlipidemia, and hypertension, was identified as an emerging factor in the formation of kidney stones.

\section{Introduction}

The prevalence of urolithiasis is more common in western countries and varies between $4 \%$ and $20 \%$. Its incidence changes according to age, gender, and geological regions and this diverse distribution can be explained by race, diet, and climatic differences. ${ }^{1}$
Hypertension, hyperlipidemia, and metabolic factors, such as obesity, increase the risk of urolithiasis. Obesity is defined as an abnormal increase in body fat and it is assessed by using the body mass index (BMI). Along with an increase in obesity, we have also experienced an increase in the incidence of associated urolithiasis. ${ }^{2}$ Waist circumference or imaging methods can be used to evaluate visceral adipose tissue. ${ }^{3}$ The risk of obesity-related diseases can increase and metabolic disorders can occur as a result of an abnormal increase in visceral adipose tissue. ${ }^{4}$

There is no data on whether the amount of visceral adipose tissue is a risk factor for urolithiasis. In this study, we evaluated whether the amount of visceral adipose tissue measured by the unenhanced computed tomography is a risk factor for urolithiasis.

\section{Methods}

We retrospectively analyzed the electronic data of 847 patients at our outpatient clinic for flank pain between August 2012 and April 2013. A total of 559 patients were excluded due to previous kidney stone operation or diagnosis of congenital urinary tract anomalies, solitary kidney, hyperparathyroidism, hyperthyroidism, chronic renal failure, liver cirrhosis, cystinuria, or missing data. In the end, we included 149 patients with kidney stones detected with unenhanced computed tomography (CT) examinations of the abdomen at 5-mm slices. This group constituted Group 1 , and another 139 healthy individuals with flank pain, but with no history of urological diseases and current kidney stones identified by CT were part of Group 2. Ultimately, 288 subjects were included in the study. Formal approvals were obtained from the local ethics committee.

Data regarding age, gender, and BMI were evaluated. BMI was calculated by dividing a patient's weight in kilograms by height in meters squared. Patient BMI was divided in 3 groups: (1) $<24.9 \mathrm{~kg} / \mathrm{m}^{2}$ as normal; (2) 25 to $29.9 \mathrm{~kg} /$ $\mathrm{m}^{2}$ as overweight; and $(3)>30 \mathrm{~kg} / \mathrm{m}^{2}$ as obese. Metabolic syndrome was defined as concurrence of BMI $>30 \mathrm{~kg} / \mathrm{m}^{2}$, 
diabetes mellitus (DM), hypertension, and hyperlipidemia.

Using CT imaging, we measured visceral adipose tissue, subcutaneous adipose tissue, the ratio of visceral adipose tissue to total amount of adipose tissue and sections taken from waist circumference at the umbilical level. We did this by determining the values between -190 and -30 Hounsfield units as fixed attenuation range as determined by Yoshizumi and Sjöström, and by using Aquarius iNtuition version 4.4.6.100.2862.5,6 The intra-abdominal adipose tissue area reserved within abdominal muscles was the visceral abdominal area (VAA), and the adipose tissue area reserved between abdominal muscles and the skin was subcutaneous abdominal area (SAA) (Fig. 1, Fig. 2). The percentage of VAA, indicating visceral obesity grade, was calculated by the following formula: VAA $\%=($ VAA VAA + SAA $) \times 100$. Patients were divided into 3 groups according to their VAA value as $<125 \mathrm{~cm}^{2}, 125$ to $180 \mathrm{~cm}^{2}$, and $>180 \mathrm{~cm}^{2}$.

Hyperlipidemia was defined as increased serum levels

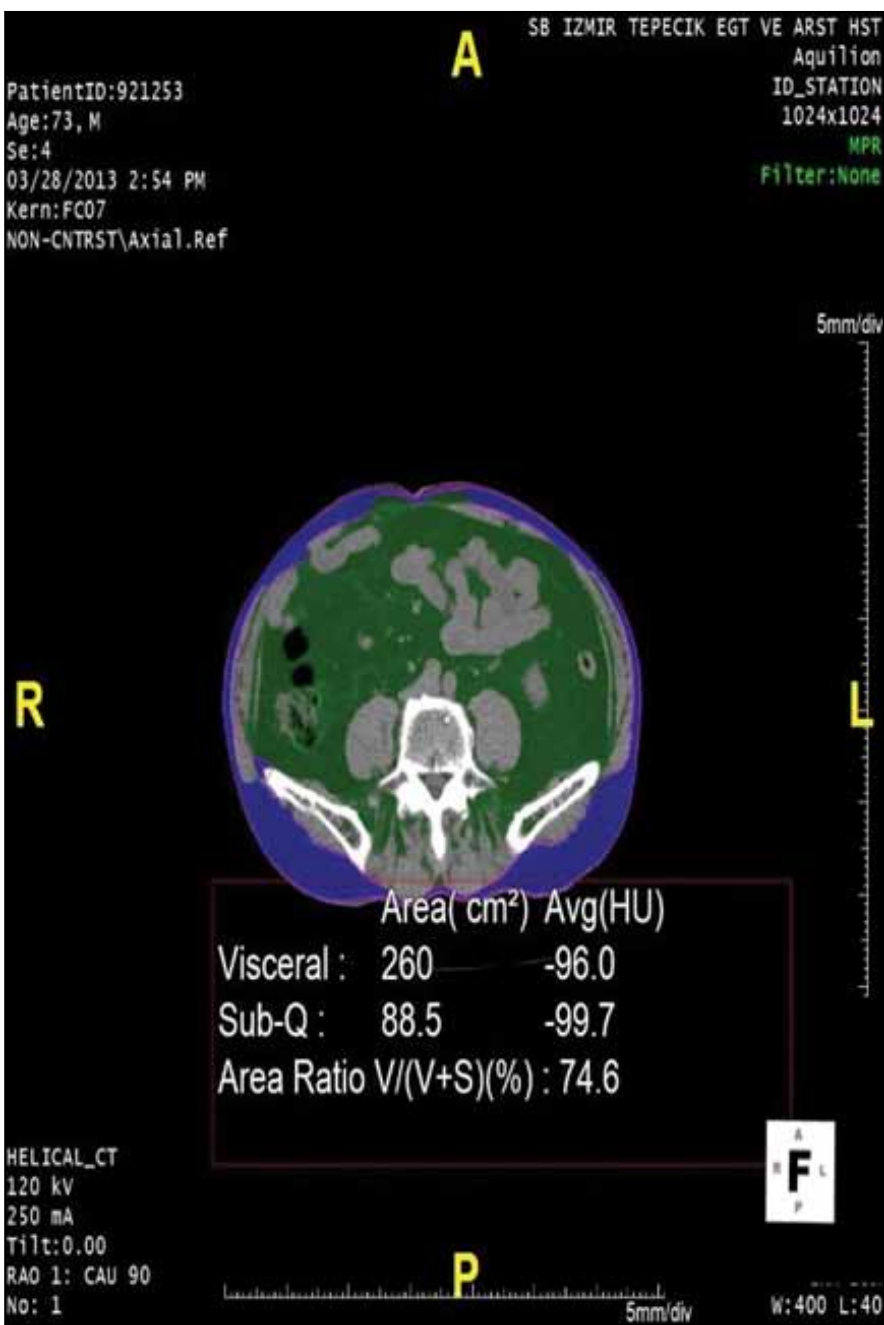

Fig. 1. Patient with wide visceral abdominal area (VAA). Green area: VAA; blue area: SAA. of any of lipids, namely total cholesterol (TC), low-density lipoprotein cholesterol (LDL-C), and triglycerides (TG).

Windows SPSS 19.0 was used in the data analysis. Chisquare and t-tests were used to evaluate the variables. Univariate and multivariate logistic regression analyses were used to evaluate the effective parameters in urolithiasis. A multivariate model included hyperlipidemia, VAA, VAA \%, SAA, hypertension, DM, BMI and VAA groups $\left(<125 \mathrm{~cm}^{2}\right.$, $\left.125-180 \mathrm{~cm}^{2},>180 \mathrm{~cm}^{2}\right)$. Statistical significance was set at $p<0.05$.

\section{Results}

The average patient age was $50.09 \pm 14.39$ (range: $21-93$ ) years in the study group, and $49.1 \pm 13.04$ (range: 19-91) years in the control group $(p=0.065)$ (Table 1$)$.

There were no significant differences in gender distribution between groups ( $p=0.27$ ), while significant differences

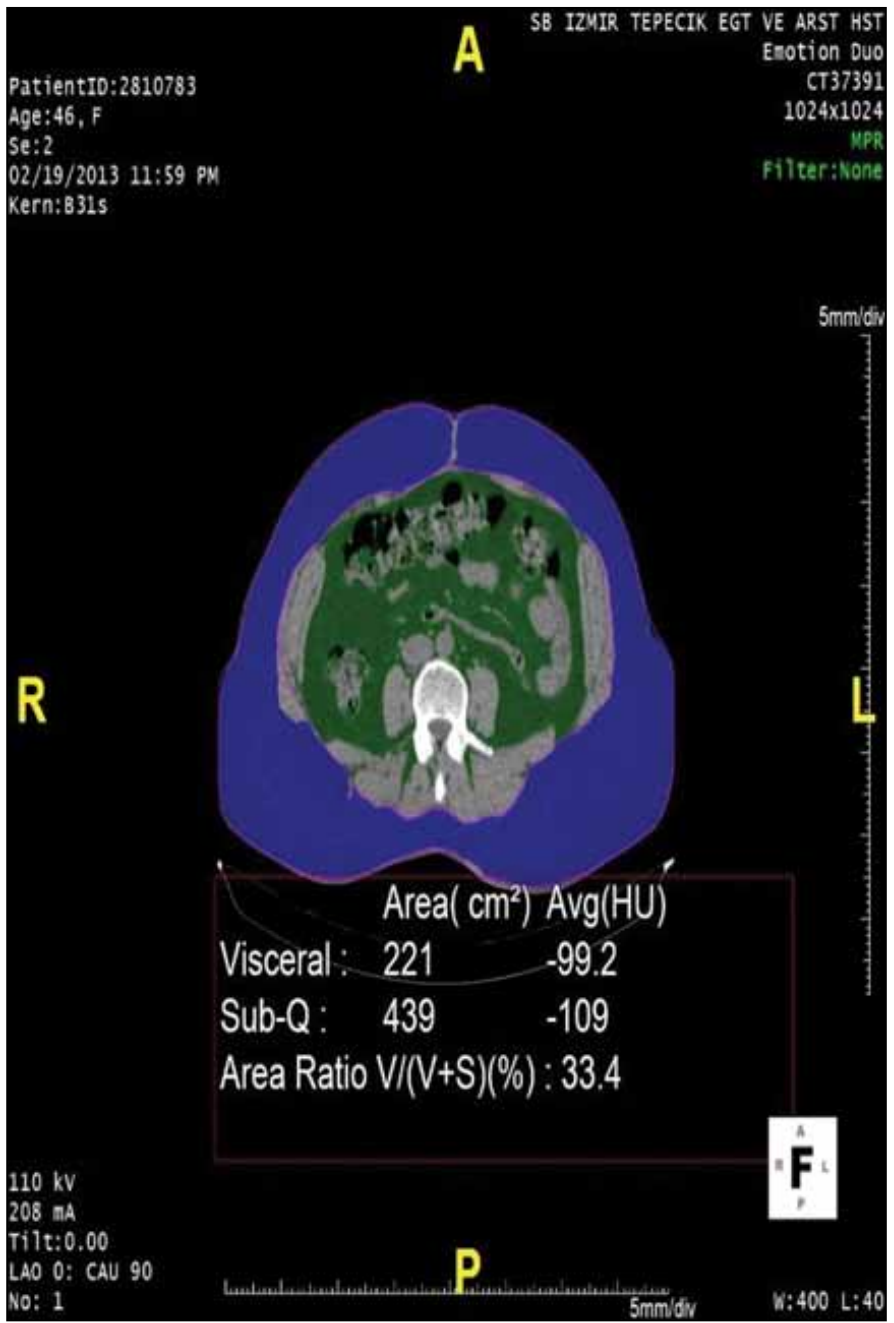

Fig. 2. Patient with wide subcutaneous abdominal area (SAA). Green area: VAA; blue area: SAA. 


\begin{tabular}{|c|c|c|c|c|c|}
\hline \multirow{2}{*}{$\begin{array}{r}\text { Parameters } \\
\text { Gender (n) }\end{array}$} & \multicolumn{2}{|c|}{ Kidney stone group } & \multicolumn{2}{|c|}{ Control group } & $p$ value \\
\hline & & & & & \\
\hline Male & \multicolumn{2}{|c|}{76} & \multicolumn{2}{|c|}{62} & 0.27 \\
\hline Female & \multicolumn{2}{|c|}{73} & \multicolumn{2}{|c|}{77} & \\
\hline Mean BMI (kg/m²) & \multicolumn{2}{|c|}{$29.1 \pm 5.38$} & \multicolumn{2}{|c|}{$27.6 \pm 5.15$} & $<0.05$ \\
\hline Mean VAA $\left(\mathrm{cm}^{2}\right)$ & \multicolumn{2}{|c|}{$186.0 \pm 72.1$} & \multicolumn{2}{|c|}{$120.2 \pm 70.1$} & $<0.05$ \\
\hline Mean SAA $\left(\mathrm{cm}^{2}\right)$ & \multicolumn{2}{|c|}{$275.9 \pm 91.6$} & \multicolumn{2}{|c|}{$261.9 \pm 87.9$} & 0.36 \\
\hline Mean $\%$ VAA & \multicolumn{2}{|c|}{$41.2 \pm 11.2$} & \multicolumn{2}{|c|}{$35.9 \pm 11.7$} & $<0.05$ \\
\hline Mean total cholesterol (mg/dL) & \multicolumn{2}{|c|}{$216.6 \pm 72.3$} & \multicolumn{2}{|c|}{$160.9 \pm 51.3$} & $<0.05$ \\
\hline Mean HDL-cholesterol (mg/dL) & \multicolumn{2}{|c|}{$42.5 \pm 9.4$} & \multicolumn{2}{|c|}{$50.4 \pm 9.6$} & $<0.05$ \\
\hline Mean LDL-cholesterol (mg/dL) & \multicolumn{2}{|c|}{$131.1 \pm 53.1$} & \multicolumn{2}{|c|}{$130.6 \pm 28.8$} & 0.65 \\
\hline Mean TG (mg/dL) & \multicolumn{2}{|c|}{$222.4 \pm 74.1$} & \multicolumn{2}{|c|}{$118.6 \pm 39.5$} & $<0.05$ \\
\hline \multirow{4}{*}{$\begin{array}{l}\text { BMI }\left(\mathrm{kg} / \mathrm{m}^{2}\right) \\
\quad<25 \\
25-30 \\
>30\end{array}$} & $\mathrm{n}$ & $\%$ & $\mathrm{n}$ & $\%$ & \\
\hline & 31 & 20.8 & 69 & 49.6 & $<0.05$ \\
\hline & 47 & 31.5 & 31 & 22.3 & $<0.05$ \\
\hline & 71 & 47.7 & 39 & 28.1 & $<0.05$ \\
\hline \multirow{2}{*}{ Metabolic syndrome } & $\mathrm{n}$ & $\%$ & $\mathrm{n}$ & $\%$ & $<0.05$ \\
\hline & 20 & 13.4 & 3 & 2.1 & \\
\hline VAA groups $\left(\mathrm{cm}^{2}\right)$ & $\mathrm{n}$ & $\%$ & $\mathrm{n}$ & $\%$ & \\
\hline$<125$ & 38 & 25.5 & 71 & 51.0 & $<0.05$ \\
\hline $125-180$ & 37 & 24.8 & 31 & 22.3 & $<0.05$ \\
\hline$>180$ & 74 & 49.7 & 37 & 26.7 & $<0.05$ \\
\hline
\end{tabular}

were found in $\mathrm{BMI}, \mathrm{VAA}, \mathrm{VSA} \% \mathrm{TC}, \mathrm{HDL}-\mathrm{C}$, and TG. In addition, both groups were split into subgroups in terms of $\mathrm{BMI}$ and $\mathrm{VAA}$, with significant differences between groups.

The prevalence of hypertension was $47.6 \%$ in the kidney stone group, and $10 \%$ in the control group $(p<0.05)$. Twenty patients $(13.4 \%)$ met the criteria of metabolic syndrome from the kidney stone group, and $3(2.1 \%)$ from the control group $(p<0.05)$.

In univariate analysis, we found that urolithiasis, hyperlipidemia, VAA, VAA\%, SAA, hypertension, BMI $>30 \mathrm{~kg} /$ $\mathrm{m}^{2}$, VAA $>180 \mathrm{~cm}^{2}$ were significant risk factors for urolithiasis. In multivariate analysis, however, hyperlipidemia, $\mathrm{VAA} \%$, hypertension, $\mathrm{VAA}>180 \mathrm{~cm}^{2}$ were significant factors (Table 2).

\section{Discussion}

The prevalence of urolithiasis is $1 \%$ to $5 \%$ in Asia, $7 \%$ in Japan, $5 \%$ to $9 \%$ in Europe, $12 \%$ in Canada, $13 \%$ to $15 \%$ in the United States, and $20.1 \%$ in Saudi Arabia. ${ }^{7}$ The following factors are considered in urolithiasis: age, gender, heredity, body composition, geographic localization, climate, diet, fluid intake, and use of drugs. ${ }^{8,9}$ Although the prevalence of urolithiasis caused by urease-secreting organisms is in black men, overall kidney stone disease is $25 \%$ to $30 \%$ less common in black men than in white men. Curhan and colleagues have indicated a history of urolithiasis in $25 \%$ of patients, and noted that even if environmental and dietary factors are controlled, the risk of urolithiasis would remain. A significant correlation has been shown between obesity and metabolic syndrome and urolithiasis. ${ }^{10,11}$ In addition, the risk of stone formation with weight gain is higher in women than in men. ${ }^{2}$

Conflicting results have been reported between kidney stone formation and gender. Urolithiasis has been reported 1.5 to 3 more times in men, and symptomatic urolithiasis

\begin{tabular}{lcc}
\hline \multicolumn{3}{l}{$\begin{array}{l}\text { Table 2. Univariate and multivariate analysis results of the } \\
\text { parameters regarding kidney stone formation }\end{array}$} \\
\hline $\begin{array}{c}\text { Univariate } \\
\boldsymbol{p} \text { value }\end{array}$ & $\begin{array}{c}\text { Multivariate } \\
\boldsymbol{p} \text { value }\end{array}$ \\
\hline Parameters & $<0.05$ & $<0.05$ \\
\hline Hyperlipidemia & $<0.05$ & 0.09 \\
VAA & $<0.05$ & $<0.05$ \\
VAA\% & $<0.05$ & 0.675 \\
SAA & $<0.05$ & $<0.05$ \\
HT & 0.07 & 0.067 \\
DM & & \\
BMI (kg/m ${ }^{2}$ ) & 0.08 & 0.97 \\
$<25$ & 0.87 & 0.11 \\
25-30 & 0.05 & 0.09 \\
$>30$ & & \\
VAA groups (cm ${ }^{2}$ ) & 0.25 & 0.91 \\
$<125$ & 0.43 & 0.16 \\
125-180 & $<0.05$ & $<0.05$ \\
$>180$ & & \\
\hline BMI: body mass index; VAA: visceral abdominal area; SAA: subcutaneous abdominal area; \\
HT: hypertension; DM: diabetes mellitus.
\end{tabular}


prevalence is $13 \%$ in men, and $4 \%$ in women. ${ }^{1}$ In a study by Cho and colleagues on 712 patients in South Korea, no significant difference was detected between women and men in the incidence of urolithiasis, whereas Daudon and colleagues in 10617 patients found a higher incidence of urolithiasis in men, in accordance with standard data. ${ }^{12,13}$ In our study, gender was not significant in the incidence of urolithiasis $(p=0.27)$.

The prevalence of obesity is increasing, with more than 1.5 billion overweight and 300 million obese people worldwide in $2005 .{ }^{14}$ It is estimated that there will be about 2.25 billion overweight and 700 million obese people in the world in 2015. In various prospective studies, with more than 200000 study patients, the incidence of urolithiasis correlated with an increase in obesity. ${ }^{211}$ In a study conducted in 2010, the risk of kidney stone disease increased with $\mathrm{BMI}$, but with a BMI above BMI $30 \mathrm{~kg} / \mathrm{m}^{2}$, the risk remained constant. ${ }^{15}$ In our study, significant differences were found in univariate analysis regarding $\mathrm{BMI}, \mathrm{VAA}$, and $\mathrm{VAA} \%$. The incidence of kidney stones has been reported to increase from $20 \%$ to $42 \%$ as BMI increased..$^{16}$ In our study, this rate showed an increase from $31 \%$ to $64 \%$. We have found significant differences in BMI between male and female patients in the kidney stone group, and the rate of obese patients was higher in men $(77.2 \%)$ compared to women $(72.6 \%)$. Del Vella and colleagues found significantly higher obesity rates in men than in women with urolithiasis. ${ }^{17}$ Similar conclusions were found by Daudonet and colleauges. ${ }^{18}$ As a result, higher BMI in men means that an increased incidence of kidney stones will also increase in men.

The methods used to evaluate VAA include waist circumference and imaging techniques. Imaging techniques are increasingly being used. Kawasaki and colleagues used ultrasound imaging (USG) and compared it with VAA in CT. Pararenal adipose tissue thickness above $10 \mathrm{~mm}$ in USG was equivalent to above $100 \mathrm{~cm}^{2}$ on VAA and about $85 \mathrm{~cm}$ on waist circumference. ${ }^{3,19}$ VAA especially above $100 \mathrm{~cm}^{2}$ has been shown to increase the risk of obesity-related diseases and induce metabolic disorders. ${ }^{4,20}$ VAA over $130 \mathrm{~cm}^{2}$ is predictive for cardiovascular diseases and diabetes. ${ }^{20}$ Zhou and colleagues found a correlation between increased VAA and higher Fuhrman grade in patients with kidney tumour. ${ }^{21}$ The authors compared patients with and without uric acid kidney stones and found significantly higher VAA in the group with uric acid kidney stones, with VAA above $125 \mathrm{~cm}^{2}$ in both groups. To our knowledge, there is no study showing higher VAA in people with kidney stones compared to those who do not have kidney stones. We have found significantly higher VAA in patients with kidney stones compared to those who do not.

Hyperlipidemia was detected in more than $30 \%$ of patients with kidney stones, and significantly higher lipid levels were detected in this group compared to the patients without kid- ney stones. ${ }^{22,23}$ Inci and colleagues found significantly higher TC levels in patients with kidney stones compared to those without, and observed an increase in calcium oxalate and uric acid stones. ${ }^{23}$ Pathogenesis between hyperlipidemia and kidney stones in rats has been explained by inflammation and damage in renal tubular cells. ${ }^{24}$ In our study, lipid levels were significantly higher in the kidney stone group.

The prevalence of metabolic syndrome ranges between $8 \%$ and $24 \%$ in men and between $7 \%$ and $43 \%$ in women. The average prevalence of metabolic syndrome in women and men are similar; for both sexes, its incidence increases with age. ${ }^{25-27}$ Metabolic syndrome is characterized by increased values of serum glucose and lipids and blood pressure, as well as central obesity. The risk of kidney stone formation increases when 2 or more of these features come together. ${ }^{10,28}$ Jeong and colleagues found that metabolic syndrome and hypertension are independent risk factors in kidney stone disease, but not for the other characteristic parameters of metabolic syndrome. ${ }^{29}$ In multivariate analysis in our study, hyperlipidemia, hypertension, VAA\% and VAA over $180 \mathrm{~cm}^{2}$ all contributed to stone formation.

Our study has its limitations, including its retrospective nature, its small sample size, possible selection bias, and missing data. The lack of stone composition data is another major limitation of our study.

\section{Conclusion}

The incidence and prevalence of kidney stone disease have been increasing in recent years and definite risk factors have been identified. In our study, we have demonstrated that VAA is a new independent risk factor for urolithiasis. Comprehensive prospective studies are needed to further elucidate the relationship between VAA and urolithiasis.

Competing interests: The authors declare no competing financial or personal interests.

This paper has been peer-reviewed.

\section{References}

1. Trinchieri A. Epidemiology of urolithiasis: An update. Clin Cases Miner Bone Metab 2008;5:101-6.

2. Taylor EN, Stampfer MJ, Curhan GC. Obesity, weight gain, and the risk of kidney stones. JAMA 2005;293:455-62. http://dx.doi.org/10.1001/jama.293.4.455

3. Kawasaki S, Aoki K, Hasegawa 0 , et al. Sonographic evaluation of visceral fat by measuring para- and perirenal fat. J Clin Ultrasound 2008;36:129-33. http://dx.doi.org/10.1002/icu.20426

4. Jeong AK, Chang JC, Keun SY. Cut-off values of visceral fat area and waist circumference: Diagnostic criteria for abdominal obesity in a Korean population. J Korean Med Sci 2006;21:1048-53. http:// dx.doi.org/10.3346/ikms.2006.21.6.1048

5. Siöström L, Kvist H, Cederblad A, et al. Determination of total adipose tissue and body fat in women by computed tomography, 40K, and tritium. Am J Physiol 1986;250:E736-45.

6. Yoshizumi T, Nakamura T, Yamane M, et al. Abdominal fat: Standardized technique for measurement at CT. Radiology 1999;211:283-6. http://dx.doi.org/10.1148/radiology.211.1.199ap15283 
7. Pak CY. Kidney stones. Lancet 1998;351:1797-801. http://dx.doi.org/10.1016/S0140 6736(98)01295-1

8. Curhan GC, Willett WC, Rimm EB, et al. A prospective study of dietary calcium and other nutrients and the risk of symptomatic kidney stones. N Engl J Med 1993;328:833-8. http://dx.doi.org/10.1056/ NEJM199303253281203

9. Holmes RP, Goodman HO, Assimos DG. Contribution of dietary oxalate to urinary oxalate excretion. Kidney Int 2001;59:270-6. http://dx.doi.org/10.1046/j.1523-1755.2001.00488.x

10. West $B$, Luke A, Durazo-Arvizu $R$, et al. Metabolic syndrome and self-reported history of kidney stones: The National Health and Nutrition Examination Survey (NHANES III) 1988-1994. Am J Kidney Dis 2008;51:741-7. http://dx.doi.org/10.1053/i.aikd.2007.12.030

11. Curhan GC, Willett WC, Rimm EB, et al. Body size and risk of kidney stones. J Am Soc Nephrol 1998;9:1645-52.

12. Cho ST, Jung S II, Myung SC, et al. Correlation of metabolic syndrome with urinary stone composition. Int J Urol 2013;20:208-13. http://dx.doi.org/10.1111/i.1442-2042.2012.03131.x

13. Daudon $M$, Doré $\mathrm{J}-\mathrm{C}$, Jungers $\mathrm{P}$, et al. Changes in stone composition according to age and gender of patients: A multivariate epidemiological approach. Urol Res 2004;32:241-7. http://dx.doi. org/10.1007/s00240-004-0421-y

14. Ng SW, Zaghloul S, Ali HI, et al. The prevalence and trends of overweight, obesity and nutrition-related non-communicable diseases in the Arabian Gulf States. Obes Rev 2011;12:1-13. http://dx.doi. org/10.1111/i.1467-789X.2010.00750.x

15. Semins MJ, Shore AD, Makary MA, et al. The association of increasing body mass index and kidney stone disease. J Urol 2010;183:571-5. http://dx.doi.org/10.1016/i.juro.2009.09.085

16. Mosli $\mathrm{H}$ a, Mosli HH. Increased body mass index is associated with larger renal calculi. Urology 2012;80:974-7. http://dx.doi.org/10.1016/i.urology.2012.07.027

17. Del Valle EE, Negri AL, Spivacow FR, et al. Metabolic diagnosis in stone formers in relation to body mass index. Urol Res 2012;40:47-52. http://dx.doi.org/10.1007/s00240-011-0392-8

18. Daudon $M$, Lacour $B$, Jungers $P$. Influence of body size on urinary stone composition in men and women. Urol Res 2006;34:193-9. http://dx.doi.org/10.1007/s00240-006-0042-8

19. El-Nahas AR, El-Assmy AM, Mansour 0 , et al. A prospective multivariate analysis of factors predicting stone disintegration by extracorporeal shock wave lithotripsy: The value of high-resolution noncontrast computed tomography. Eur Urol 2007;51:1688-93. http://dx.doi.org/10.1016/i.eururo.2006.11.048
20. Després JP, Lamarche B. Effects of diet and physical activity on adiposity and body fat distribution: Implications for the prevention of cardiovascular disease. Nutr Res Rev 1993;6:137-59. http://dx.doi. org/10.1079/NRR19930010

21. Zhou T, Watts K, Agalliu I, et al. Effects of visceral fat area and other metabolic parameters on stone composition in patients undergoing percutaneous nephrolithotomy. J Urol 2013;190:1416-20. http:// dx.doi.org/10.1016/i.juro.2013.05.016

22. Kadlec $A 0$, Greco $K$, Fridirici $Z$, et al. Metabolic syndrome and urinary stone composition: What factors matter most? Urology 2012;80:805-10. http://dx.doi.org/10.1016/j.urology.2012.05.011

23. Inci $M$, Demirtas $A$, Sarli B, et al. Association between body mass index, lipid profiles, and types of urinary stones. Ren Fail 2012;34:1140-3. http://dx.doi.org/10.3109/0886022X.2012.713298

24. Tsuïhata $M$, Yoshioka I, Tsujimura $A$, et al. Why does atorvastatin inhibit renal crystal retention? Urol Res 2011;39:379-83. http://dx.doi.org/10.1007/s00240-011-0370-1

25. Cameron AJ, Shaw JE, Zimmet PZ. The metabolic syndrome: Prevalence in worldwide populations. Endocrinol Metab Clin North Am 2004;33:351-75. http://dx.doi.org/10.1016/i.ecl.2004.03.005

26. Ford ES, Giles WH, Dietz WH. Prevalence of the metabolic syndrome among US adults: Findings from the third National Health and Nutrition Examination Survey. JAMA 2002;287:356-9. http://dx.doi. org/10.1001/jama.287.3.356

27. Azizi F, Salehi P, Etemadi A, et al. Prevalence of metabolic syndrome in an urban population: Tehran Lipid and Glucose Study. Diabetes Res Clin Pract 2003;61:29-37. http://dx.doi.org/10.1016/S0168$8227(03) 00066-4$

28. Rendina D, Mossetti G, De Filippo G, et al. Association between metabolic syndrome and nephrolithiasis in an inpatient population in southern Italy: Role of gender, hypertension and abdominal obesity. Nephrol Dial Transplant 2009;24:900-6. http://dx.doi.org/10.1093/ndt/gfn548

29. Jeong IG, Kang T, Bang JK, et al. Association between metabolic syndrome and the presence of kidney stones in a screened population. Am J Kidney Dis 2011;58:383-8. http://dx.doi.org/10.1053/i. ajkd.2011.03.021

Correspondence: Dr. Ilker Akarken, Kemalpasa State Hospital, 8 Eylül Mah, 35710, Kemalpasa, Izmir, Turkey; ilkerakarken@gmail.com 